\title{
Research into the views of two child reference groups on the arts in research concerning wellbeing
}

Jones, P. Mercieca, D. \& Munday, E. (2018) Research into the views of two child reference groups on the arts in research concerning wellbeing, Arts \& Health, DOI: $\underline{10.1080 / 17533015.2018 .1534248}$

\begin{abstract}
Background: This paper explores an aspect of the process and outcomes of two children's reference groups: the ways the young members of the reference groups consider the role of the arts in research concerning wellbeing.

Methods: Two case studies draw on qualitative data from the projects offering insight into child reference group work over the life of a research project: from recommendations to implementation.

Results: The findings demonstrate that both reference groups enabled the research to achieve a fuller engagement with meaning making in relation to data collection by consulting with children.

Conclusions: The data reveals how the members offered 'insider knowledge' to the researchers concerning the role of the arts in research concerning wellbeing. Themes within the analysis about the impact of the reference group's knowledge and recommendations on the research project's data collection methods include the role of the arts connected to empathy, safety and confidentiality and in relation to difference and choice.
\end{abstract}

The Research in England was supported by the LankellyChase Foundation

Key words reference groups child participation arts and wellbeing 


\section{Introduction}

This article reports on the experiences of two child reference groups, relating to two national research projects. One, 'Views of Psychotherapy', was a two year research project which aimed to evoke, represent and understand children's perspectives of their engagement in psychotherapy interventions in residential care in Malta. The other, 'Children's experiences and views on disadvantage,' was an eighteen month project in England funded by the LankellyChase Foundation that offered children and young people the opportunity to be involved in research to present their experiences and views about disadvantage. It was delivered in different sites, working with partner organisations in the fields of education, mental health and community development. . Reference groups consist of members of the population being researched. They have been defined as a space within which co-reflexive activities can assist researchers to consider their research approaches, assumptions, methodologies and methods and to arrive at new knowledge (Moore, Noble-Carr \& McArthur, 2015). This paper explores an aspect of the process and outcomes of two children's reference groups: the ways the young members of the reference groups consider the roles of the arts in such research. Sharing mutual concerns, this article reports on the processes within both experiences to deepen mutual understanding of the work. Two case studies, one from each project, analyse the nature and impact of child reference group work over the life of the research projects: from recommendations to implementation. 


\section{Background}

The overall aims of both child reference groups were parallel: to support the development of research methods that take into consideration reference group members' reflections about how children would like to be asked about their experiences and knowledge. The following questions informed our research into the reference group:

Were there benefits from the reference group in relation to the research projects 'Views of Psychotherapy' and 'Children's experiences and views on disadvantage'?

What can be learned from the experience of the reference group about theory and practice relating to child reference group work?

The invitations to take part in the groups made clear that they would inform the practice of the research projects and that the reference groups themselves would be written about as part of reporting on the research. The reference groups were facilitated by researchers from their respective projects. This article focuses on how the reference group members offered 'insider knowledge' (Moore et al., 2015) to the researchers concerning the role of the arts in designing data collection methods; how this was implemented in the research projects and the perceptions of the child participants on the value and impact of the recommendations.

\section{Reference groups as a form of participation}

Moore et al. (2015) perceive the use of reference groups as subscribing to the belief that researchers need to refer to members of the groups they are to research, who are thought of as having access to different 'insider' knowledge from the researcher. They argue that when children are involved in this way, their views may make the research process more effective, for example by advising on the appropriateness of data collection methods. However, they comment on the lack of record and analysis concerning the practice and value of child reference groups. McCarry (2012) also identifies this absence and addresses it by inviting researchers to report on and evaluate 
children's participation in relation to specific research projects and the benefits that children will gain from such participation within any particular context.

\section{Research, child participation, the arts and wellbeing}

The relationship between the arts and participatory research with children, exploring the arts, wellbeing, participation and child 'voice', is one that has received a degree of attention in recent years. In this context, we are approaching 'wellbeing' within the framework of Camfield, Struli and Woodhead's “concept of psychosocial well-being (which) acknowledges the importance of intimate relations and social participation, and can also foreground subjective meanings and experiences, namely children's evaluations of their lives according to their values and local norms" (2008, p. 27). Bradbury-Jones and Taylor summarise the "underpinning philosophy" of such "participatory approaches" in research with children as "clear: a commitment to accessing voice and to creating space for these voices to be heard" (2015, p. 162). Cowell, Herron and Hockenberry (2011), for example, included material in their research with children attending a cancer and hematology center about whether they thought arts activities were "helpful" in relation to their situation (2011, p. 178), and O'Neill and Moore (2016) have examined the use of mixed visual and discursive group methods to explore children's perceptions and awareness of mental health issues. The literature notes, though, the dearth of enquiry related to this relationship. Emberley and Davhula have argued that "the notion of children's 'voices' as a construct used to frame their lack of power and agency, overlooks how they employ tools, such as music, to voice their agency in “dynamic, articulate, and meaningful ways" (2016, p. 1). Authors such as Hill (2006), for example, note recent attempts to redress children being normally passive with respect to method choice in research, and identifies the need to consider children's expressed views on methods used by adults to obtain children's perspectives. Even within texts exploring the relationship of the arts to research that aims to empower children and support their agency, the literature notes that there is little work to date either about children's views about the role of the arts and wellbeing within such research or 
about the role and impact of reference groups in such research involving children (Hill, 2006;

Hutchfield \& Coren, 2011).

\section{Response to the literature}

This article aims to advance understanding of children's participation in research by offering insights into the two reference groups. It draws on the two experiences in order to enrich understandings of the role and nature of child reference groups in relation to participatory research connected to children's wellbeing and the arts, reflecting McCarry's (2012) call for the need to gain insights by reporting on specific contexts. By comparing two projects, the analysis will examine whether, and how, the reference groups brought specific responses to the particular contexts of the research. The article also reviews the uses made of the recommendations made by reference groups in the actual conduct of the research undertaken in Malta and England, responding to critiques identified in the literature which call for a need to specify and evaluate the outcomes, benefits and limitations of reference groups rather than merely assuming them as inherently beneficial (Moore et al., 2015). Though the projects were created in response to different areas of children's lives and conducted separately, they share an attempt to deepen understanding of the role of child reference groups in working with sensitive topics concerning wellbeing and to gain insights into reference group members' perceptions on the role of the arts in such research with children. Our work responds to the call voiced by Fleming (2013), that in order for young people's active involvement in research to develop, there needs to be more reporting, interchange and dialogue between researchers committed to participative research to help deepen insight into this emergent area of theory and practice. This article is an attempt to create such dialogue, and to offer insight into child reference groups and the recommendations made in relation to the arts and wellbeing.

\section{Research approach and methodology}


The article offers two case studies, one from each research project. Each case study focuses on one of the major themes common to both reference groups. This theme concerns the members' perspectives on role of the arts within the intended research. Each case study is delivered in two parts, illustrated below. Case Study Part A concerns data from the reference group, Part B from the project itself:

\begin{tabular}{|c|c|}
\hline Case Study Data set & Rationale for inclusion \\
\hline Idy Part A & \\
\hline $\begin{array}{l}\text { 1. Data from the reference group on the use of } \\
\text { the arts in data collection methods for the } \\
\text { intended research concerning child wellbeing. }\end{array}$ & $\begin{array}{l}\text { 1. To communicate reference group perceptions } \\
\text { and recommendations on the arts in data } \\
\text { collection. }\end{array}$ \\
\hline Case Study Part B & \\
\hline $\begin{array}{l}\text { 2. Data from the research projects where data } \\
\text { collection methods using the arts were } \\
\text { implemented. }\end{array}$ & $\begin{array}{l}\text { 2. To illustrate how the research responded to } \\
\text { the reference group recommendations on the arts } \\
\text { within their data collection methods. }\end{array}$ \\
\hline $\begin{array}{l}\text { 3. Feedback from child research project } \\
\text { participants on their experiences of the data } \\
\text { collection methods. }\end{array}$ & $\begin{array}{l}\text { 3. To illustrate child participant perceptions on } \\
\text { their experience of the arts as a data collection } \\
\text { method. }\end{array}$ \\
\hline
\end{tabular}

The three data sets enable the article to offer a unique insight into child reference group work over the life of the research projects: from recommendations to implementation. For clarity, children in the reference group are referred to as 'members', and those involved in the research groups are described as 'participants'. The sets considered together illustrate the reference group members' recommendations (Case Study Part A), offering insight into their implementation by the 
project researchers and enable a review of how the research participants responded to the implemented recommendations (Case Study Part B). The analysis of the two projects together create the opportunity for dialogue and insight into the richness of the two different contexts.

\section{Malta context}

The overall aims of the research project were to identify, represent and understand children's views of their engagement in psychotherapy interventions. It also sought to address how an understanding of children's perspectives can contribute to service development in Malta. The project also aimed to represent children's feedback about the methods used to engage them in the research. There are particular complexities in conceptualising and undertaking research in relation to children's participation in the field of mental health services and out of home care (Cavet \& Sloper, 2004; Midgley, Ansaldo, \& Target, 2014; Polvere, 2014 ). Recent research with children in residential care (National Commission for Child Policy \& Strategy, 2014) and in foster care (DeBono \& Muscat Azzopardi, 2016) in Malta described this context as one which some children found it "difficult to navigate and did not sufficiently empower their participation in decision making" (DeBono \& Muscat Azzopardi, 2016, p. 14). Within the context of research with children transiting from out of home care to adulthood, Lushey and Munro (2015) refer to previously researched barriers to children's participation in such research which identify problems including power differences, coupled with low self-esteem and motivation. Securing such children's participation is perceived by Lushey and Munro (2015) as a potential way to facilitate children's active engagement in research, minimise power differentials, gain access to insider knowledge and thus enhance the quality of collected data.

\section{England context}

The research project, 'Children's experiences and views on disadvantage,' aimed to develop ways of working that maximised the potential of participatory research to enable children and young people experiencing disadvantage to represent their experiences and views. Research questions 
included 'What are effective ways to develop and sustain relationships with children experiencing disadvantage and to initiate and sustain participatory research for them to document and report on their own lives?' The research involved collaboration between University College London and four different partner organisations, Chilypep (www.Chilypep.org.uk), Blank Canvas, (http://www.mdproductionsltd.com/blank-canvas.html), School and Family Works (https://theschoolandfamilyworks.co.uk) and UK MAC (https://www.mac-uk.org/) who worked with children and young people who may be 'hard to reach', or excluded, from conventional routes to research participation connected to their experiences of social exclusion (McCarry, 2012; Shaw, Brady \& Davey, 2011). Offers to participate were made to children involved in each partner organisation and four research groups were formed. As discussed in Sections 3.5 and 3.6, below, the reference group and each research group explored its own associations and meanings concerning disadvantage. The relationships between wellbeing and disadvantage was a theme that occurred in all the groups' work. It is present in the material within the reference group, for example, in their seeing disadvantage as connected to 'mental illness', 'invisible illness' and 'vulnerability' (see Table 1). The research group discussed in this article identified the aspects of disadvantage that they particularly wished to focus upon in their research. This concerned the connection between disadvantage, neighbourhood and wellbeing. In the research group, this can be seen in their developing and playing characters who are young carers living in isolating and dangerous neighbourhoods.

\section{Reference group participants}

All children within a Maltese out of home care residential context were invited to participate in the reference group through an information leaflet. Six children aged between 12 and 18 agreed to participate and all were included. In total the group met five times.

In England the reference group was open to children who had been involved in research with Chilypep, a child participation organisation based in a deprived area of a Northern city. The 
children had been involved in Chilypep projects over the past year, and the membership reflected these areas of experience. The projects had involved children who were living with mental health difficulties, were young carers and who were refugees. Invitations, through a reference group information leaflet, were sent out to children who had worked with Chilypep and we were able to include everyone who expressed interest. A group of eight young people, aged 15-19, met five times within the life of the project.

\section{Structure and content of the reference groups.}

Both reference groups had a similar structure. The work with each group began with considering overall aims, approach to content, the ethics for the group, including consent to participate and an agreement that there would be feedback to members on how the reference group's work was being reflected in the design and implementation of the research project. Content was negotiated with the groups, reflecting the overall aims, stated above.

\section{Ethics}

Ethical approvals for the reference groups and the research projects as a whole were obtained via the University of Malta Research Ethics Committee and the UCL Institute of Education's Research Ethics Committee. In each situation, information sheets were provided for potential child reference group members and child research project participants and for parent/guardians. Signed consent for participation was gained from each child and from parents or guardians. Consent included an understanding that data from the reference group and the research projects could be used in reports and articles about the work. All data is anonymised and pseudonyms are used.

Within the context of the reference groups, there were a number of particular ethical issues that arose. These concerned the sharing of data from the projects, the nature of the subject matter and members' responses to it. In relation to the English project, the Youth Expert Panel had all 
taken part in projects themselves and had knowledge of research ethics: part of their role in the reference group was to advise the project on its ethics procedures in relation to working with children. This included their feedback on information sheets, consent forms and processes. In the introduction to the work and in the consent process, the facilitators discussed ethical issues with the group. It was clarified that all data from the young researcher projects shared within the reference group would be anonymised and that data was securely stored, within password protected laptops. The facilitators made clear, within the invitation to take part in the reference group, that the focus was children and disadvantage, so that participants understood the nature of the subject and made an informed decision to take part based on this knowledge. In relation to the Maltese reference group, a primary ethical concern was making sure that the research did not negatively impact the children's psychotherapy. Thus only children who had been in therapy for at least six months were invited to participate in the reference group. Research information material was also sent to children who had decided to stop attending therapy. It was agreed that participating children would receive support, follow-up and further therapy if they wished to. During the reference group process, for example, a participant approached the researcher to access the service once again and this was acted upon. During the reference group process in Malta, every effort was made to distinguish between research and therapeutic interventions (Hutchfield and Coren, 2011). During the informed consent process the researcher informed children that deciding whether to participate or not would in no way impact upon their attending therapy. Moreover, the reference group was conducted in a separate room from the spaces usually used for therapy. Children were also informed about the confidentiality of their responses, and that pseudonyms were to be used in every written report and transcript. In terms of safeguarding issues, at the end of each reference group meeting, the researcher provided children with the opportunity to debrief.

\section{Data collection}


The data collection method for both reference groups and the research project involved recordings of discussions, and written or drawn material created by the members of the reference group and by participants in the research project. The data was subject to thematic analysis, identifying common themes related to the research questions.

\section{Results}

The findings are contained in the following two Case Studies. The first concerns the Malta project, the second the English project. Each Case Study is in two parts. The first, Part A, contains extracts of data from a reference group's ideas and commentaries on communicating the research to participants. One of the main areas of recommendations in each group concerned data collection methods in relation to the arts, and this is the theme focused upon within this article. The second, Part B, contains extracts of data from the research project itself. This illustrates the ways the researchers reflected the recommendations in the work with child participants and concerns how child participants engaged with the arts methods, along with reflection from the participants on their experience of the arts.

\section{Case Study 1}

\section{Case Study 1A: Reference group 'Views of Psychotherapy', Malta}

In debating communication with future research participants, members suggested particular kinds of attention to the data collection methods. They spoke about the need for the researchers not to rely exclusively on the spoken word. Mick expressed concern regarding children feeling annoyed and frustrated if the researcher relied only on the spoken word and connected this to the risk of disengagement. Steve linked the importance of not relying only on the spoken word to the issue of access and maintained that "if only spoken words are used not everyone will be able to say something".

Mick highlighted the use of photos, which allow the child to "speak more". Steve added 
"instead of talking they can draw because you can understand more". When the researcher asked him to explain further, he commented, "because you feel more his feeling". Simone added, "if he does not feel comfortable to talk, he will be able to draw". Simone emphasised the effectiveness of drama: "with drama meaning comes out more". Glenn remarked that drama helps to bring out the children's feelings. Simone linked the use of a creative medium as a means to facilitate the child's expression in a research context which he described as "having to sit down and being expected to speak even if he feels embarrassed. ... But if he uses his talent he may be able to say what he wants to say".

The researcher sought to explore the idea, expressed by some members, of creative media being seen as better and more engaging:

Researcher: But can't children just talk about their feeling?

Simone: Maybe they are embarrassed to say their feelings.

Glenn: Drama is not necessarily better, but it needs to be seen as another different option.

At times, members alluded to the complexity of using non-verbal means of data collection rather than merely highlighting the assumed benefits of such media. Simone introduced the issue of age differences: "It's different, if they are youths or children. Youths are more mature, maybe a youth feels comfortable, but younger children may not feel comfortable replying to a direct question". He also explained that if children do not feel comfortable speaking, they might still not be comfortable speaking with a puppet.

Members saw value in proposing different media in terms of the significance of offering choices. Simone spoke directly about offering choices and maintained: "If children have the opportunity to make a choice, there is a higher probability of children opening up". At the same time, Glenn associated being offered choices with the risk of an ensuing chaos or disorder, as he feared everyone doing whatever they wanted might cause problems in communicating. 


\section{Case Study 1B: Research Project 'Views of Psychotherapy', Malta}

This section explores how within the Views of Psychotherapy research project, the researcher responded to the reference group recommendations and perceptions in terms of both not relying only on the spoken word during data collection and in offering a choice of methods to participants. The approach to using data collection methods was developed as a direct response to the members' recommendations. Participants in the research were of a similar age to those in the reference group.

The researcher included the use of role, puppets (as an option for younger participants), a cartoon strip, photo prompts and a conventional semi-structured interview as possible methods from which research participants would be invited to choose. Reference group participants also suggested the use of feeling cards which initially the researcher had discarded in line with literature (Hutchfield \& Coren, 2011) which suggests the ethical principle of creating a distinction between research and therapeutic interventions. Yet reference group participants actually referred to their positive experience of using feeling cards in therapy and based their suggestion on such an experience. The researcher decided to accept this suggestion and explored with group members what kind of cards would be helpful, ultimately resulting in designing a set of cards together with the group.

In terms of implementing the use of creative art techniques as data collection methods, one of the Views of Psychotherapy participants, Bob, for example, decided to use an adaptation of the Attending Therapy Scenario (Davies, Wright, Drake, \& Bunting, 2009). This tool involves presenting children with two images: one showing a child in a therapy session and other one showing a child leaving therapy. Children are then involved in semi-structured interviews about the photographs. In response to the questions, Bob created a fictitious story about a child who needed to access psychotherapy. Bob seemed to need to speak from a distanced position about this fictitious child's story of therapy. Towards the end of the interview, when asked about how his own 
experience of therapy related to the created story, he was able to talk about the similarities and differences.

During a subsequent member checking interview (Lincoln \& Guba, 1985) Bob gave feedback on the experience of the research interview. Within the following conversation, Bob communicates his understanding regarding the usefulness of a more distanced approach to data collection rather than talking about one's own experience directly, especially as related to sensitive topics, such as talking about therapy, in research:

Bob: It's like you take some of your own stuff and you also put it on him (the created character), he is narrating ... It's like I wanted to tell a story about a boy I do not even know, so in order to create it you take a bit from yourself, the stuff you feel.

Interviewer: So you take your stuff and you put them on his story.

Bob: It's like you match them a bit ... Just like I explained in the beginning, kind of, because obviously you do not know who this boy is sort of, so in order to create a story, you kind of, I dunno know whether you are understanding me, you take a bit of yours. ... You make him kind of, you understand?

Interviewer: You create the boy? It's easier I think

Interviewer: Why easier?

Bob: ... Because it's like you are not speaking about yourself, you can go ahead and speak about the other, in fact you would be kind of speaking for yourself and the other person (interviewer) would not know because he thinks you are creating a story, got it? So it's easier to just go ahead and speak.

\section{Case study 2}

Case Study 2A: Reference group 'Children's experiences and views on disadvantage', England 
The researchers facilitating the reference group created an opportunity to explore associations with the focus of the intended research, 'disadvantage', followed by work to explore the implementation of the research questions through the approach to data collection methods. The activity to consider data collection methods had three sections to it. The first aimed to enable the group to orientate themselves with the focus of the research: 'disadvantage'. The second activity aimed to enable the group to consider the different options for data collection methods connected to the theme. The third asked for their input on factors to take into account in designing and conducting data collection methods. The following data is from the first activity. The reference group were asked to share the first word that came to mind when we use the word 'disadvantage'. Participants wrote these down simultaneously.

Table 1 Disadvantage in text here

The following data is from the second activity. The group mentioned interviews, questionnaires and focus groups. Discussion concerned the different ways that material could be evoked and communicated within such data collection methods, taking into account the specific theme of 'disadvantage' and that participants would be children, and we would be working with different age groups in the four sites (two sites aged 7-11, one aged 7-13 and another 16-21). This moved into the third activity. The group decided to share their ideas by drawing up a list of matters that they felt the researchers should take into account in designing and conducting data collection methods, given the specific challenges of dealing with what the group considered as a sensitive theme. The following are all the points made by the group:

\section{Table 2 Recommendations in text here}

Table 2 reflects the order that the reference group members created the items in and follows their trains of thought and associations. The group emphasised the values of the arts within the 
research - the use of stories, characters and pictures, for example. These are linked to awareness, supporting communication and understanding, confidentiality, cultural differences and to making some of the process enjoyable.

The reference group members also advised the researchers to ask participants about their experience of the research. Areas identified by members included feedback on areas such as clarity, learning and their experiences of the different activities.

\section{Case Study 2B: Research project 'Children's experiences and views on disadvantage, England'}

The researchers reflected these points (Table 2) in the design and implementation of the project as a direct response to the reference group recommendations. In the initial contact with the groups, for example, participants were offered the option of talking, writing and image making as a first exploration of their associations with disadvantage. The following images are from the first meeting with a group of 9 children living in an English inner city, aged 7-11. The aim of the activity was to begin to explore their perceptions, thoughts and experiences of disadvantage. The researchers simply made materials available, invited people to work with them in any way and to share as much, or as little, as they wished to the rest of the group, following some time for exploration. Out of the nine children, two created images alone, six used a combination of image and text and one child used text only. The following offers a sample of image only, and image and text.

Figure $1 \quad$ Anna (aged 7) in text here

Figure 2 Chris (aged 12) in text here 
The group decided to look at the relationship between disadvantage, the neighbourhood you live in and wellbeing. They looked at a variety of ways of exploring this including drawing, interviewing each other, taking photographs and improvisation. The group decided to use drawing and role-play by developing two fictional characters 'Majesty' and 'Wilfie'. They designed characters through creating a life size image in order to reflect and further explore some of their experiences and views of disadvantage. The group had the opportunity to improvise in role, taking the part of the character or an interviewer. The group could then discuss any part of this process and the themes, or their responses to the themes. The following concerns the character, 'Wilfie'.

\section{Extract from improvisation}

The group took it in turns to play 'Wilfie' and his 'Interviewer', exploring stories of their lives and their day-to-day experiences. The following is an extract:

Charlie as 'Interviewer': Is this area happy?

Kerry as 'Wilfie': Well, no, because there's like... It's very dark, but not as in, like, the night's dark, it like feels dark; it's very miserable and you don't see anyone really around there. It's not like a really safe place to be cause there's all robbers. I wouldn't really go out because it's more of like I have to look after my mum cause there's no one else there for her.

'Interviewer': Do you feel safe in that area?

'Wilfie': $\quad$ No. Because we haven’t got no money we can't like really move anywhere.

'Interviewer': Um, on a normal day, do you face any difficult challenges?

'Wilfie': Well, yes, because I've got to look after my mum and I'm, like, only young. The way I have to look after my mum and everything, it's like, I face a lot of things, like, 
if she needs someone, like if she needs help I've got to do everything for her. No one else is there for her.

'Interviewer': Do you like looking after your mum, or is it just very difficult?

'Wilfie': It can be difficult at times, but at the same time I do it because I get to learn new things and hopefully when I'm older I'll get to be a carer.

A questionnaire was devised, reflecting reference group recommendations to obtain feedback from the project participants, containing closed and open questions. The following presents the responses to questions about activities within the research and comments about child participant views on the data collection methods.

Table 3 Questionnaire Extract - summary of responses from the 11 participants - in text here

\section{Discussion}

The following analysis of the data reflects the positions taken by Hill (2006) and Fleming (2013) in that the work of the reference groups will be analysed, examining children's participation in the research process, exploring the specific differences and contexts of enquiry for both case studies and the value placed by the reference group on the arts within the approach to data collection. The discussion considers the processes within both experiences to deepen mutual understanding of the findings. The analysis will focus on a finding common to both groups: the arts are positioned by members as a key element in communicating and exploring children's experiences and thoughts about wellbeing within the data collection process. The following material considers the data in relation to the aims of the research into the reference groups: to examine the 
relationships between the reference groups' recommendations on the development of research methods and the impact of these on the research projects. Within both contexts group recommendations were fully implemented. By connecting the recommendations of the reference group members with feedback from the child participants on their experience of the research, it is possible to gain insight into the impact and efficacy of the recommendations.

\section{Empathy, safety and the arts}

One of the insights that can be drawn from both reference groups is the ways that members advocated processes connected to empathy and the arts. Within both groups, children communicated to the researchers their lived experience. They show empathy and invite the researchers to empathise with participants who are living with different kinds of disadvantage or experience of psychotherapy in out of home provision and what it might be like to be asked about their lives. One of the themes within this attention to empathy concerns the arts and sensitivity to the act of enquiry, connected to developmental issues and to participants' levels of awareness of, and insight into, their own situations.Within the Maltese group in Case Study 1A, Steve's comment reflects the connection between empathy and the arts: drawing as a data collection method enables the child better to express themselves and for the researcher to empathise more with the child participant: "you will feel more his feeling”. Within the English group, in Case Study 2A, one chain represented in the members' list (Table 2) is:

- Age-appropriate languages

- Story examples

- Multiple different stories showing people from different backgrounds

- Pictures

The advice to use age-appropriate language is followed by comments on the values of stories and pictures to communicate and create dialogue. Here story-telling and images are seen as 
a way to create access, to communicate and to investigate experiences. Safety and confidentiality are also connected to arts processes, for example, in the use of characters to express and explore material. The four linked points in the list (Table 2) are:

- Nothing too sensitive or extreme

- Be aware that children may not be aware of their own disadvantage/segregation

- Use characters to make confidentiality easier

- Communicate that disadvantage is not always obvious and comes in many forms

The notion of 'characters' is seen to be one whereby role and drama enable themes and experiences to be expressed directly, but they need not be identified by an individual as their own. Here the group show their awareness of the sensitivity of material and the problem of exposure, "Nothing too sensitive or extreme", or stigma in relation to "segregation" and the role of confidentiality. Joy and enjoyment were seen by the reference group as important themes: that the research should provide pleasure, with reference group members imagining that this would offer engagement and also make looking at disadvantage a safer and more manageable process to experience. This was seen as especially important given the theme of the research: "Not too serious" - "Make some of the process enjoyable" and "Nothing too sensitive or extreme", with creative work being seen as connected to this, for example in the recommendation to use characters.

The impact and value of the reference groups' perceptions and guidance is reflected in the data extracts from the research projects in Case Study 1B and Case Study 2B. They show how these areas of advice were reflected in the data collection methods developed within each research project and offer insights into the perceptions and views of the arts made by the research participants. In Case Study 1B, Bob's feedback about the use of such a technique reveals his awareness and evaluation that it is "easier" to engage with material, arguing that "you can go ahead and speak about the other" even though, "you would be kind of speaking for yourself". In Case Study 2B, the 
use made and responses to games and improvisation illustrate the value of the advice of the reference group on the arts as enabling personal themes to be engaged with and expressed, without them being claimed and expressed by an individual as their own life details and as being experienced as "fun". The images and role-play involving 'Wilfie' enable the child participants to empathise with the role they created and to reflect themes of living in unsafe areas, being a young carer and the experience of isolation. This reflects the process of empathy in creating roles described by Jones, "empathy encourages emotional resonance, identification and emotional involvement within any dramatic work..." but because it is a dramatic fictional role rather than a direct representation of the self, it enables "a more distanced perspective on a life situation" (2007, p.95). 'Wilfie' enabled the exploration and communication of these themes, whilst offering different levels of connection and ownership as well as safety and enjoyment advocated by the reference group in its advice. The child participants could create characters and empathise with their situations and experience, but with the safety of not directly claiming them as their own. Feedback from participants in the research confirm the accuracy of the reference group's perceptions and advice. Examples of this include comments in Table 3, above:

- That they had fun activities

- We got to enjoy it whilst discussing serious things

- It wasn't completely serious but we had fun

- That is wasn't completely serious we still had fun

- It wasn’t completely serous and we all got to share our ideas

It is also reflected in feedback on the activities (see Table 3) with all participants strongly agreeing, or agreeing, that the arts activities helped explore the theme of disadvantage and all participants strongly agreeing that the activities helped them to communicate their ideas. 


\section{Difference, choice and the arts}

Another finding concerned both reference groups' perceptions on the role of the arts in relation to difference. This considered how individual children might engage differently with art based data collection tools. Again, though the theme is common, each group related it to their specific context. The arts are seen by the Maltese group to enable and facilitate access for some children: "if only spoken words are used not everyone will be able to say something". As can be seen in Case Study 1A, whilst discussing the possibility of different kinds of engagements related also to the child's age, the group members foregrounded the importance of trust within the researcher-child relationship where art based tools were seen as communicative media within the relationship. Within this relationship, reference group members highlighted the importance of the researcher's sensitivity to children's different circumstances and engagements. This ran parallel to the reference group members' understanding of the sensitive nature of the research project and consideration for the participant's comfort levels and potential embarrassment when speaking about feelings associated with psychotherapy.

Within the English reference group, the notion of the specific contextual meanings of 'difference' are also seen as connected to the arts in relation to story making, image making and communication and being a young carer, living in an unsafe neighbourhood, in Case Study $2 \mathrm{~A}$. Difference is presented in a variety of ways by the group within their list (Table 2). It is present in that members suggest the researchers create diverse stories with children as a way of reflecting "people from different backgrounds". They also see difference in that children may be at varied developmental levels concerning age and awareness of disadvantage; that children ("even of the same age)" may have different levels of understanding and that this difference can be responded to by helping communication and meaning-making through stories and pictures. They relate difference 
to the offering of choice: that children may have different affinities for picture making or story making.

Whilst both reference groups identify the role of the arts as a data collection method in relation to difference, the two groups consider this to have a particular emphasis related to their context. The value of the English reference group's advice, for example, to use images is evidenced in the task of drawing and writing about associations and experiences of disadvantage in Case Study 2B. Figures 1 and 2 illustrate the ways in which imagery enabled the child research participants to communicate in ways that reflect the reference group's suggestions and valuing of the arts. A key aspect of this value reflects the reference groups' advice about the arts, age and difference in that Figure 1 is by a seven year old and Figure 2 by a twelve year old. Here the seven year old creates image alone, whereas the twelve year old combines text and image. This difference was reflected in the overall research group response, with younger participants using images and single words where older children tended to combine more complex written text within their images, as reflected in Figure 2. This may reflect differences in age concerning communication, but also differences in personal choice about communication or levels of literacy. In Case Study 1B, Bob's own reflections regarding the act of making a choice of photographs as an expressive medium allows us to understand how being given a choice may actually increase the "probability of children opening up": a central suggestion within the Malta reference group. Bob's reflection on his own expressive process underscores the value of the child participants being offered arts processes to reflect their differences and preferences and being given a choice regarding how they express themselves within the research.

\section{Conclusion}

The presentation and analysis of the two Case Studies answers the calls identified within the literature for communicating research which explores the nature and value of participatory research with children, especially concerning reference group work and children's views on the nature and 
value of the arts in enquiry connected to wellbeing. Considering the two projects has shown the importance of insider knowledge and how this is context specific in considering the value and benefits to research with children of reference groups involving child members. This analysis has looked at the specific differences and contexts of enquiry rather than generalising about processes (McCarry, 2012). The Case Studies, by combining examples of recommendations and implementation, evidence the value and impact of the reference groups. They show how researchers were able to develop and employ data collection methods that reflected the issues identified by the groups concerning the role of the arts in enabling different, contextual processes connected to empathy, safety, difference, development and enjoyment. In particular, the article has shown the values of the group members' perceptions of the arts as enabling engagement with complex and sensitive material and of creating access to activities that enabled child participants to share perceptions and experiences through image and role in the two different contexts of experiences of psychotherapy and of disadvantage. 


\section{References}

Bradbury-Jones, C., \& Taylor, J. (2015). Engaging with children as co-researchers: challenges, counter-challenges and solutions. International Journal of Social Research Methodology, 18(2), 161-173.

Camfield, L., Struli, N., \& Woodhead, M. (2008). Children's Well-being in Contexts of Poverty: Approaches to Research, Monitoring and Participation. Oxford: Oxford University Department of International Development, Young Lives.

Cavet, J., \& Sloper, P. (2004). Participation of Disabled Children in Individual Decisions About Their Lives and in Public Decisions About Service Development. Children \& Society, 18(4), 278290.

Cowell, E., Herron, C., \& Hockenberry, M. (2011). The impact of an arts program in a children's cancer and hematology center. Arts \& Health, 3(2), 173-181.

Davies, J., Wright, J., Drake, S., \& Bunting, J. (2009). “By Listening Hard”: Developing a ServiceUser Feedback System for Adopted and Fostered Children in Receipt of Mental Health Services. Adoption \& Fostering, 33(4), 19-33.

DeBono, D., \& Muscat Azzopardi, M. (2016). Let Me Thrive: A Research Study on Foster Care in Malta. Retrieved from https://dspace.mah.se/handle/2043/21212. 
Emberly, A., \& Davhula, L.A. (2016). My music, my voice: musicality, culture and childhood in Vhavenda communities. Childhood: A Global Journal of Child Research, 23(3), 438-454.

Fleming, J. (2013). Young People's Participation - Where Next? Children and Society, 27(6), 484495.

Hill, M. (2006). Children's voices on ways of having a voice: Children's and young people's perspectives on methods of consultation. Childhood: A Global Journal of Child Research, 13(1), 69-89.

Hutchfield, J., \& Coren, E. (2011). The Child's Voice in Service Evaluation: Ethical and Methodological Issues. Child Abuse Review, 20(3), 173-186.

Lincoln, Y. S. \& Guba, E. G. (1985). Naturalistic Inquiry. Newbury Park, CA: Sage Publications. Jones, P. (2007). Drama As Therapy. London: Routledge.

Lushey, C. J., \& Munro, E. R. (2015). Participatory peer research methodology: An effective method for obtaining young people's perspectives on transitions from care to adulthood? Qualitative Social Work, 14(4), 522-537.

McCarry, M. (2012). Who benefits? A critical reflection of children and young people's participation in sensitive research. International Journal of Social Research Methodology, 15(1) 5568.

Moore, T., Noble-Carr, D., \& McArthur, M. (2015). Changing things for the better: the use of children and young people's reference groups in social research. International Journal of Social Research Methodology, 19(2), 241-256.

National Commission for Child Policy \& Strategy (2014). The voice of the child in care. Malta: Chamber of Advocates. 
O'Neill, M., and Moore, K. (2016). 'Keeping my mind strong': enabling children to discuss and explore issues relating to their perceptions of positive mental health through the arts. Journal of Research in Nursing, 21(7), 544-567.

Polvere, L. (2014). Agency in Institutionalised Youth: A Critical Inquiry. Children \& Society, 28(3), 182-193.

Shaw, C., Brady, L., \& Davey, C. (2011). Guidelines for Research with Children and Young People, London: National Children's Bureau Research Centre. 